This is an electronic reprint of the original article. This reprint may differ from the original in pagination and typographic detail.

Author(s): Rasti Behbahani, Amin

Title: $\quad$ A Survey of University Students' Knowledge of Vocabulary Learning Strategies and Influential Factors in Middle East

Year: $\quad 2016$

Version:

Please cite the original version:

Rasti Behbahani, A. (2016). A Survey of University Students' Knowledge of Vocabulary Learning Strategies and Influential Factors in Middle East. Journal of Language Teaching and Research, 7(4), 646-654.

https://doi.org/10.17507/jltr.0704.03

All material supplied via JYX is protected by copyright and other intellectual property rights, and duplication or sale of all or part of any of the repository collections is not permitted, except that material may be duplicated by you for your research use or educational purposes in electronic or print form. You must obtain permission for any other use. Electronic or print copies may not be offered, whether for sale or otherwise to anyone who is not an authorised user. 


\title{
A Survey of University Students' Knowledge of Vocabulary Learning Strategies and Influential Factors in Middle East
}

\author{
Amin Rasti Behbahani, \\ University of Jyvaskyla, Finland
}

\begin{abstract}
In this study, the most and the least common vocabulary learning strategies was explored among Eastern Mediterranean University international students. Besides, the role of personal factors such as gender and English proficiency level of students were considered. After distributing the questionnaire, the data were analyzed applying t-test and ANOVA. It was revealed that the level of importance of vocabulary learning strategy use was moderate for the EMU international students. Furthermore, it was found that metacognitive strategies and social strategies are the most and the least common vocabulary learning strategies respectively utilized by EMU international students for learning vocabulary. Regarding the role of gender and proficiency level, the t-test and ANOVA results indicated that gender was an effective factor; whereas, proficiency was not an influential factor in preference of students for using vocabulary learning strategies. Male students preferred detrimental strategies but females preferred metacognitive strategies.
\end{abstract}

Keywords: Vocabulary Learning Strategies, Proficiency, Gender, EFL Context

\section{Introduction}

"Vocabulary plays a crucial role in English language acquisition, particularly for college students" (He, 2010). If students acquire a deep and rich vocabulary knowledge-base they can convey their message more efficiently. But learning vocabulary is not easy. New words will be forgotten if they are not used. Practitioners and applied linguists have always been trying to not only emphasize the importance of vocabulary learning but also propose a way for efficient learning of new vocabulary items.

Recently, an effective tool for accelerating language learning is learning strategies. Oxford (1990) emphasizes on the influential role of language learning strategies and defines them as "behaviors, actions, and techniques that students apply to ameliorate their progress in producing and comprehending L2” (p. 2). She believes if students learn the strategies they will be faster and better in their learning route. Gu (1994) and Schmitt (1997), considering language learning strategies, provided “Vocabulary Learning Strategies” (VLS). They hold that if language learners learn VLS, their vocabulary learning enhances this knowledge assists the process of acquisition.

Different learners have different methods and preferences of learning because of the effects of various personal variables and contextual factors. Factors like gender, level of proficiency, age, etc can distinguish learners in their choice of methods for vocabulary learning, especially VLS. Recent researches have revealed the probable impact of these factors (Siriwan, 2007; Lachini, 2008; Amirian \& Hashemifar, 2013). These factors also vary in different contexts of the 
study. For example, language learners, in Rainkamol's (2008) study in a Malaysian university, chose VLS different from Hogben and Lawson’s (1996) in an Australian university.

There have been many studies on various aspects of language learning strategies in the past decades (LLS hereafter). However, the studies involving language teachers in the EFL context are very limited. So far, the pertinent research has shown the importance of the LLS for the language learning process, as well as positive educational outcomes. Previous studies on the characteristics of the "good language learner" as well as "unsuccessful language learners" has proved that language learning strategies plays an important role.

As it is discussed, knowing about language learning strategies, especially vocabulary learning strategies are very important for language learners. On the other hands, studying the factors that can affect the choice of these strategies seems necessary. Besides, being aware of difference in choosing these strategies due to difference in context and lack of this study in an international university like Eastern Mediterranean University, It seems necessary to conduct a research studying vocabulary learning strategies while considering factors like gender and language proficiency.

Considering the importance of vocabulary learning strategies and factors like gender and proficiency, conducting researches on VLS choice in different contexts is crucial. Lack of such a study, in this paper, the researcher tries to investigate the VLS choice among male and female international students in different levels of proficiency at Eastern Mediterranean University (EMU), North Cyprus. The results of this study could be useful for international universities where students need to attend English language preparatory courses as well as EMU.

\subsection{Significance of the Study:}

This study's outcome is significant for both English language teachers and researchers. English language teachers at EMU can use the findings of this study to help their student learn vocabulary items as fruitful as possible. Knowing the most and the least VLS among international students and being aware of the impact of factors like gender and proficiency level help these teachers to provide the most sufficient and proper way of teaching vocabulary and vocabulary learning strategy. The researchers can use the results of this study to improve their knowledge about the vocabulary learning strategy and come up with a possible theory or hypothesis that make their future studies more scientific.

\section{Theoretical Framework of the Study}

Vocabulary knowledge is very essential for language learners. Teaching them vocabulary learning strategies can be very productive in teaching vocabularies. Fan (2003) believes that there are five steps in the most of the vocabulary learning strategies: " 1 . facing with the word, 2. getting an image of the word in mind, 3. learning the meaning, 4. making a strong connection between form and meaning, 5. using the word”. Holding this concept, many researchers studied different aspects of vocabulary learning strategies. For example, Oxford (1990) emphasizes on encouraging language learners to learn VLS they makes learners autonomous and responsible for their own learning. Benson (2001) also believes that EFL/ESL learners' level of independency will increase if they were taught vocabulary learning strategies explicitly. Nation (1990) believes that one of the most important ways for learning language is knowing and using vocabulary 
learning strategies. Schmitt and Schmitt (1995) posits the importance of vocabulary learning strategies knowledge they believe that educational programs and syllabuses must contain teaching VLS. Lajtai (2013) also found that language learners who are aware of vocabulary learning strategies outperform others with little knowledge of vocabulary learning strategies at Pecs University. Graves (1987) believes that students must try to learn independently. In so doing, they must learn how to use strategies for learning. In vocabulary learning, which is a very personal activity, teaching language learners to use vocabulary learning strategies is essential. Willerman and Melvin (1979) found that students, when learning vocabulary, use different kinds of strategies after a month studying French. They conclude that VLS learning is necessary. Nation (2001) introduces the learning burden in vocabulary learning as the amount of effort that learners needs for learning new vocabulary items. He adds "different words have different learning burdens for learners with different backgrounds and each of the aspects of what it means to know a word can contribute to its learning burden” (p. 23). Teachers must help students to learn VLS for decreasing the learning burden of learning new vocabulary items. Oxford and Crookall (1990) advise that teachers must try to find the best way for teaching vocabularies effectively. They continue by emphasizing the knowledge of VLS by teachers as well as students. They put that teachers must be aware of different types of vocabulary learning strategies because greater knowledge of vocabulary means greater progress in language learning.

\subsection{Factors Affecting Vocabulary Learning Strategy Use}

\subsubsection{The Most and the Least Common VLSs}

As the importance of vocabulary learning strategy was discussed in previous session, many researchers tried to identify most and least common vocabulary learning strategies that were used by language learners in different contexts.

Hogben and Lawson (1996) observed 15 students who were trying to study and learn new Italian words to know what types of vocabulary learning strategies they use. Most of EFL learners try to learn new vocabulary items by repetition of new words and their meanings as their vocabulary learning strategy. While the grammatical or physical aspects of the words were paid little attention.

Riankamol (2008) investigated the vocabulary learning strategies adopted by English gifted students of Udomuska School in the first semester. Using Schmitt taxonomy, a 25-item questionnaire adopted for the purpose of the study. Using frequency, percentages, and means, it was divulged that high proficient students at that school were using metacognitive strategies frequently. They also use "I learn words by listening to vocabulary CDs" as less frequent strategy in that category.

Asgari and Bin Mostapha (2011) examined the types of vocabulary learning strategies by TESL students at University Putra Malaysia. By an open-ended interview, 10 students were asked about their type of strategy use. They concluded that the most popular strategies were learning through reading, using monolingual dictionary, using various English language media, and use of the words in daily conversation.

Amirian and Heshmatifar (2013) searched for most and least common strategies among Iranian EFL learners at Hakim Sabzevari University, Iran. They asked 74 male and female 
learners by Schmitt vocabulary learning strategy questionnaire. The results revealed that determination strategies and social strategies were the most and the least common types the learners use generally in that context respectively.

\subsubsection{Gender}

Gender has always been considered as an important issue in language learning. Being important, many researchers hold an empty space for gender in their studies. In vocabulary learning strategy studies, gender is also controversial. Results are different in this area of study.

Siriwan (2007), in her thesis, explored the role of different learner's variable in vocabulary learning strategy choice at the Rajabhat University. Regarding gender, she found that it has a significant role in choosing vocabulary learning strategies.

Heidari Soureshjani (2011), in a comparative study, explored gender-oriented vocabulary learning strategy among Iranian EFL learners. He observed a significant difference in male and female use of vocabulary learning strategy. He ascertained that proper vocabulary learning strategy must be used considering the sex of the learners.

Hassanzadeh, Khatib, and Rezaei (2011) investigated the role of gender in vocabulary learning strategy use among 146 undergraduate EFL students, after evaluating their level of proficiency, at the University of Vali-e Asr, in Rafsanjaan, Iran. They found no significance difference between learners' gender and selection of vocabulary learning strategy.

Pourshahian, Rezvani Kalajahi, and Yousefi Azarfam (2012) studied variation in vocabulary learning strategies use according to gender difference in Turkish EFL learners. The results of their study revealed that gender is highly correlated with vocabulary learning strategy use. Female respondents' frequency of vocabulary strategy use was slightly higher than males in metacognitive and psycholinguistic vocabulary learning strategies.

\subsubsection{Level of Proficiency}

Reckoning the level of proficiency, many researchers have studied its relation with vocabulary learning strategy use to know the possible correlations.

Lachini (2008) investigated the impact of level of proficiency in L2 on Creative, Reflective, Effective, Active, and Motivated (CREAM) vocabulary learning strategies. 120 language learners were participated in his study. A 60-item questionnaire was administered in a 5-point Likert scale and distributed among them with three different levels of proficiency. Using MANOVA, it was revealed that these types of strategies are used variably among learners based on their level of language proficiency. Participants, in the same level of proficiency, use the same strategies with same frequencies.

Barekat and Karami (2012) studied the possible correlation between proficiency level of Iranian EFL learners and their vocabulary learning strategy use in Rasht. Categorizing learners into three levels of proficiency: elementary, intermediate, and advanced, they asked the subjects about their vocabulary learning strategies by a questionnaire. It was revealed that proficiency level is highly correlated with frequency of vocabulary learning strategy use. Advanced learners were using most common vocabulary learning strategies noticeably more than intermediate and elementary level learners. 
Ajideh and Jafari (2013) explored whether there were differences in the selection of vocabulary learning strategies among Iranian EFL learners with different levels of proficiency. They selected 102 participants randomly for the study after their proficiency levels were evaluated. Participants received questionnaire regarding the aim of the study. They found that there were significant differences among frequency of learners' choice for using vocabulary learning strategies in different levels of proficiency statistically.

Lin-Fang (2013) studied the effects of different learners' variables, such as motivation, family background, and proficiency level, on the use of vocabulary learning strategies. He conducted his study on 450 first grade students at Fooyin University. His results revealed that proficient learners were better users of vocabulary learning strategies. They watched English TV programs, listened to radio in medium of English, read English newspapers, and playing computer games in English more than less proficient learners.

Azimi Mohammad Abadi and Baradaran (2013) conducted a study to investigate the "relationship between learner autonomy and vocabulary learning strategy with regard to different level of proficiency". In their study, by using two proficiency tests they classified learners and 190 female and male EFL learners were asked to fill in questionnaires. The results revealed that proficiency level is highly positively correlated with learners' autonomy and vocabulary learning strategy use among learners. Learners, in advance level, developed more autonomy with regard to vocabulary learning strategy use than intermediate level learners.

Khezrlu and Sadeghi (2013), in their study named: self regulated vocabulary strategy use, considered learner's variables like proficiency. Their experimental groups experienced learning new vocabulary items in the form of printed textual definition with pictures, glosses provided in L1, and glosses presented in L2. Finally, they were asked to fill in a self-regulated capacity vocabulary learning strategy questionnaire. The results showed that learner's variables were influential on final results but not for proficiency level. There was a weak correlation between learners' level of proficiency and their use of vocabulary learning strategies.

\section{Research Questions:}

Knowing the necessity of learning the most helpful vocabulary learning strategies and the effective learner's variables, I have tried to answer the following questions in this paper:

1. To what extent do International students at Eastern Mediterranean University use vocabulary learning strategies?

2. What are the most and the least common vocabulary learning strategies applied by international students at Eastern Mediterranean University?

3. Is there any significant difference in vocabulary learning strategy regarding gender?

4. Does English proficiency level affect using vocabulary learning strategies among groups?

\section{Methodology}

\subsection{Descriptive Research:}


This study is descriptive in design. Using this method the current status of phenomena is interpreted (Farhady, 2008, P. 144). There are three groups of descriptive studies. Survey is the most famous one. Using questionnaires and interviews data are collected (Dornyei, 2007). The role of personal factors such as gender and proficiency level of the students on their use of vocabulary learning strategies are also studied. Thus this study is correlational as well.

\subsection{Context:}

This study was conducted in an EFL context. The study was conducted at Modern Language Division, Eastern Mediterranean University, North Cyprus. Students who are going to begin their study at postgraduate levels such as master and doctorate, if their proficiency scores in English proficiency test does not meet the language requirements, they must pass one or two deficiency language courses in Modern Language Division.

\subsection{Participants:}

76 international male and female language learners answered the questionnaire in this study. 48 males and 28 females were asked to participate in this study. Their age ranged from 22 to 47 years old. All of them had at least one deficiency English language course to pass. They were from different countries involving Asia to Europe. They were mostly from countries such as Iran, Turkey, North Cyprus, Libya, Iraq, Syria, Kazakhstan, Tajikistan, Russia, Austria, and Ukraine.

\subsection{Instruments:}

Two instruments were used in this study. At first, the English language proficiency test, designed by the School of Foreign Languages at Eastern Mediterranean University and is a standardized test considering the reliability and the validity, was used for measuring proficiency level of the language learners. The top score, in this test, was 100.

A 5 points Likert-scale questionnaire containing 52 questions adapting from Schmitt's (1997) taxonomy of vocabulary learning strategies was used as the second instrument (Riankamol, 2008; Pourshahian \& Rezvani Kalajahi, 2012; Amirian \& Hashemifar, 2013). The questionnaire contains three sections: a consent letter, personal information questions, and the batteries. According to Schmitt (1997), the learning vocabulary strategies are divided into five main categories in which these 52 questions are placed: Determination Strategies (DET) or strategies that are used by learners themselves for finding the meaning of the words or retention of the meaning without taking any help from others, Social Strategies (SOC) or strategies that learners use for finding or retention of the meaning by interacting with other people, Memory Strategies (MEM) or Strategies that are utilized by the learners for retention of the words by relating them to their previous knowledge, Cognitive Strategies (COG) or strategies for vocabulary learning that engage learners more in mechanical processing rather than mental processing, and Metacognitive Strategies (MET) or strategies that learners use for managing their cognitive processes such as decision making, monitoring, and evaluating learner's progress.

\subsection{Procedure:}

To conduct the study, after preparing the adapted questionnaire, the researcher requested the permission for conducting the research at the university. When the permission was offered, the researchers distributed the questionnaire among the participants. It takes three days to distribute 
and collect the questionnaires. Finally, questionnaires were analyzed by the computer and results revealed.

\subsection{Data Analysis:}

For finding the most and the least common vocabulary learning strategies used by the learners, frequency, mean, and standard deviation were applied. To find the possible role of language proficiency level and gender in using VLS, T-test and ANOVA was applied. Data were analyzed by Statistical Package for the Social Sciences (SPSS) for windows, version 21.

\section{Results}

\subsection{Research Question 1:}

To what extent do International students at Eastern Mediterranean University use vocabulary learning strategies?

Regarding the following established means categorization, the data were analyzed (Griffiths, 2007; Oxford, 1990); accordingly, The highest mean is 3.5-5. The analysis of the EMU international students' survey data revealed that VLS importance was low $(\mathrm{M}=2.8621)$. In other words, the use of vocabulary learning strategies is moderate between the EMU international students. The results are presented in the Table 1 below. A is the overall average level of importance.

Table 1. EMU International Students’ Vocabulary Learning Strategy Use

\begin{tabular}{lccr}
\hline & $\mathrm{N}$ & Mean & Std. Deviation \\
\hline A & 76 & 2.8621 & .42076 \\
Valid N (listwise) & 76 & & \\
\hline
\end{tabular}

5.2 Research Question 2:

Table 2. The Most and the Least Common Vocabulary Learning Strategies Among EMU Students 


\begin{tabular}{lccr}
\hline & $\mathrm{N}$ & Mean & Std. Deviation \\
\hline MET & 76 & 3.0711 & .57383 \\
DET & 76 & 3.0320 & .67677 \\
COG & 76 & 2.9649 & .72127 \\
MEM & 76 & & .54225 \\
SOC & 76 & 2.8427 & .65868 \\
\hline
\end{tabular}

What are the most and the least common vocabulary learning strategies used by international students at Eastern Mediterranean University?

The most common strategies that EMU international students used for vocabulary learning are metacognitive strategies (MET) with mean of 3.0711. Whereas, the least common type of vocabulary learning strategy was social strategies with mean of 2.6165.

Besides, it was revealed that among all 52 VLSs in the questionnaire, Take notes in class, Continue to study over time, Use the vocabulary section in your textbook, Use English-language media, Connect the word to its synonyms and antonyms, and Study the spelling of a word with numbers 43, 52, 48, 19, and 28 respectively in the questionnaire were the most common vocabulary learning strategies among EMU international students. Moreover, Skip or pass new word, Peg Method, Ask teacher for L1 translation, and Underline initial letter of the word owning numbers 51, 16, 8, and 32 respectively in the questionnaire were the least common vocabulary learning strategies among EMU international students. Results are listed in the table 3 below.

Table 3. The Most and the Least Common Vocabulary Learning Strategies Among EMU Students

\begin{tabular}{llccr}
\hline & & $\mathrm{N}$ & Mean & Std. Deviation \\
\hline & Q43 & 76 & 3.87 & .914 \\
The Most & Q52 & 76 & 3.71 & .964 \\
& Q44 & 76 & 3.61 & .981 \\
& & & & 1.386
\end{tabular}




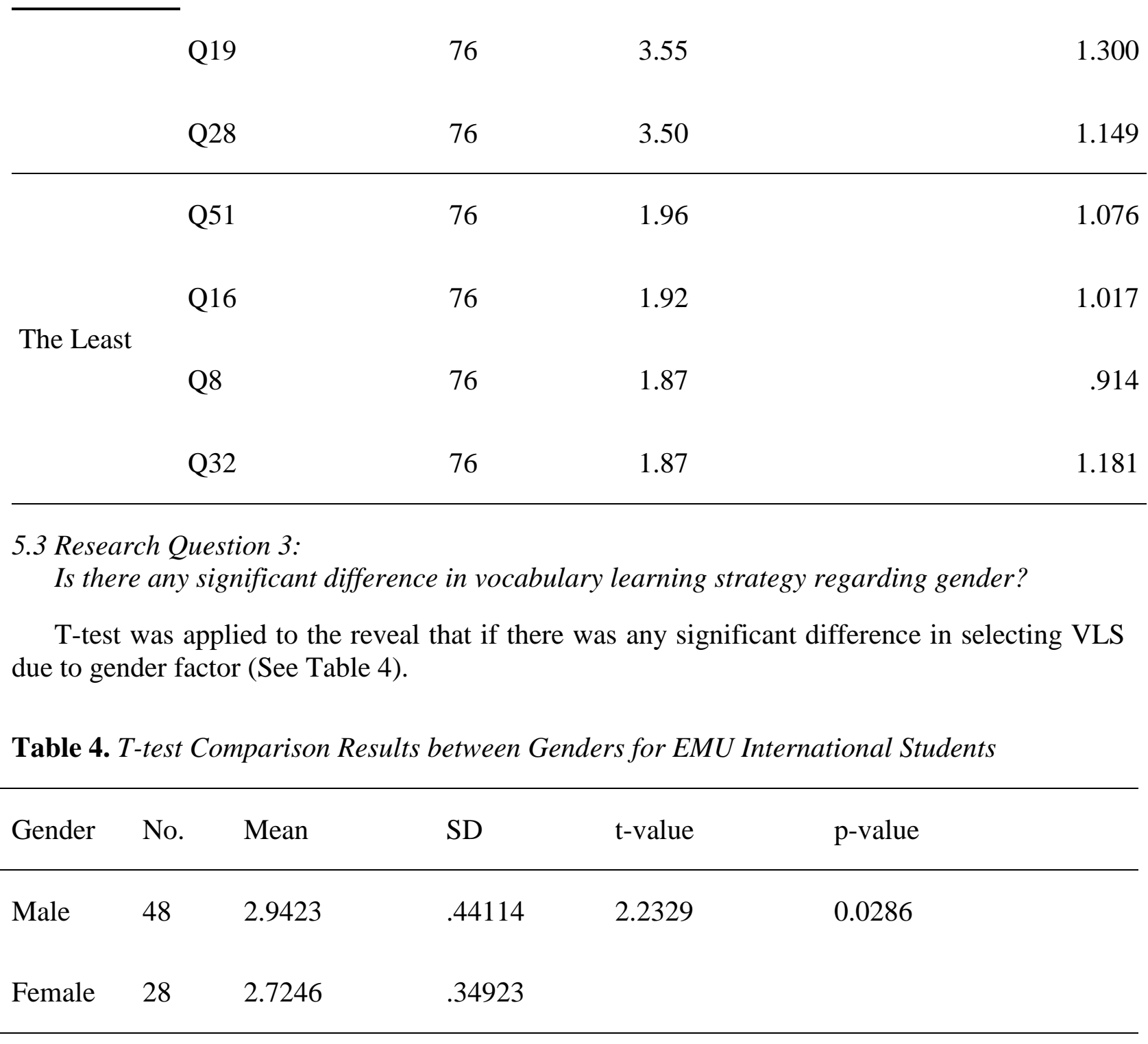

Confidence level of significance established as of 0.05 . There were significant differences between males and females in their choices of VLS Since the p-value for the predictive variable was lower than 0.05 .

It is also revealed that males tended to use Determination Strategies (DET) $(M=3.080)$ more than female; whereas, females tended to use Metacognitive Strategies (MET) (M=3.257) more than males (Table $5 \& 6$ ).

Table 5. Strategies Used by EMU International Male Students

N Mean

Std. Deviation 


\begin{tabular}{lccc}
\hline DET & 48 & 3.0804 & .74313 \\
COG & 48 & 3.0486 & .82797 \\
MEM & 48 & 2.9810 & .56204 \\
MET & 48 & 2.9625 & .58150 \\
SOC & 48 & 2.7143 & .52303 \\
\hline
\end{tabular}

Table 6. Strategies Used by EMU International Female Students

\begin{tabular}{lccr}
\hline & $\mathrm{N}$ & Mean & Std. Deviation \\
\hline MET & 28 & 3.2571 & .51885 \\
DET & 28 & 2.9490 & .54740 \\
COG & 28 & & .46686 \\
MEM & 28 & 2.8214 & .41786 \\
SOC & 28 & 2.6056 & .82636 \\
\hline
\end{tabular}

Moreover the results shows that EMU international male students prefer to use VLSs such as Take notes in class, Connect the word to its synonyms and antonyms, Study the spelling of a word, Use new words in sentences, Use the vocabulary section in your textbook, Monolingual dictionaries, Analyze part of speech, Continue to study over time, Associate the word with its coordinates, and Group words together to study them with item numbers 43, 19, 28, 26, 44, 7, 1, 52, 18, and 24 respectively the most. While most of them didn't tend to use VLS such as Skip or pass new word, Peg Method, and Underline initial letter of the word with item numbers 51, 16, and 32 respectively. (Table 7) 
Table 7. Strategies Used by EMU International Male Students

\begin{tabular}{|c|c|c|c|c|}
\hline & & $\mathrm{N}$ & Mean & Std. Deviation \\
\hline & Q43 & 48 & 4.00 & .875 \\
\hline & Q19 & 48 & 3.81 & 1.142 \\
\hline & Q28 & 48 & 3.75 & 1.212 \\
\hline & Q26 & 48 & 3.63 & .937 \\
\hline & Q44 & 48 & 3.56 & 1.009 \\
\hline \multicolumn{5}{|l|}{ The Most } \\
\hline & Q7 & 48 & 3.56 & 1.335 \\
\hline & Q1 & 48 & 3.50 & 1.130 \\
\hline & Q52 & 48 & 3.50 & .945 \\
\hline & Q18 & 48 & 3.50 & 1.011 \\
\hline & Q24 & 48 & 3.50 & 1.130 \\
\hline & Q51 & 48 & 1.88 & .937 \\
\hline \multirow[t]{2}{*}{ The Least } & Q16 & 48 & 1.81 & .960 \\
\hline & Q32 & 48 & 1.63 & .937 \\
\hline
\end{tabular}

For females, the results divulged that EMU international students mostly tend to use Continue to study over time, Use English-language media, Use the vocabulary section in your textbook, Image word's meaning, Guess from textual context, Take notes in class, and Connect word to a personal experience with numbers 52, 48, 44, 22, 5, 43, 17, and 3 respectively for vocabulary learning. Additionally, females prefer not to use mostly VLSs such as Put English labels on 
physical objects, Configuration, Use Key word Method, and Ask teacher for L1 translation with item numbers 46, 33, 34, and 8 respectively. (Table 8)

Table 8. Strategies Used by EMU International Female Students

\begin{tabular}{|c|c|c|c|c|}
\hline & & $\mathrm{N}$ & Mean & Std. Deviation \\
\hline \multirow{8}{*}{ The Most } & Q52 & 28 & 4.07 & .900 \\
\hline & Q48 & 28 & 3.89 & .994 \\
\hline & Q44 & 28 & 3.68 & .945 \\
\hline & Q22 & 28 & 3.68 & 1.056 \\
\hline & Q5 & 28 & 3.68 & .945 \\
\hline & Q43 & 28 & 3.64 & .951 \\
\hline & Q17 & 28 & 3.64 & .826 \\
\hline & Q3 & 28 & 3.57 & .690 \\
\hline \multirow{5}{*}{ The Least } & Q46 & 28 & 1.93 & 1.120 \\
\hline & Q33 & 28 & 1.93 & 1.016 \\
\hline & & & & \\
\hline & Q34 & 28 & 1.89 & .994 \\
\hline & Q8 & 28 & 1.64 & 1.062 \\
\hline
\end{tabular}

\subsection{Research Question 4:}

Does English proficiency level affect using vocabulary learning strategies among groups?

In order to figure out whether or not there are any significant differences between EMU international students concerning their level of proficiency in English, ANOVA was applied to the related survey data. Participants, in this study, were divided into three proficiency level based 
on their score in EMU proficiency test: Elementary (40-60) $(M=2.66)$, Intermediate (61-80) $(\mathrm{M}=2.92)$, and Advanced (81-100) $(\mathrm{M}=2.90)$. Considering the mean of the groups, we can state that the importance of using VLSs is moderate for all participants regarding their proficiency level.

The results of ANOVA also show that there are no significance differences among groups concerning their level of proficiency. As the results show in the table 9 below, p-value (0.135) is higher than level of significance (0.05). Thus, there are not any significance differences among three groups of elementary, intermediate, and advanced students in their choices for using VLSs.

Table. 9 ANOVA Results for the EMU International Students in Terms of English Proficiency

\begin{tabular}{lccccc}
\hline Groups & No. & Mean & SD & f-value & p-value \\
\hline Elementary & 15 & 2.66 & 0.24 & 2.201 & 0.118 \\
Intermediate & 18 & 2.92 & 0.41 & \\
Advanced & 43 & 2.90 & 0.45 &
\end{tabular}

\section{Discussion}

In this study, it was tried to investigate the most and the least common vocabulary learning strategies among EMU international students. Additionally, the role of factors like gender and the level of proficiency in English were considered. Considering the first question: to what extent do International students at Eastern Mediterranean University use vocabulary learning strategies?, it was revealed that using vocabulary learning strategies for learning and retention of new vocabulary items is moderate. The main reason for this outcome could be lack of enough knowledge about these strategies. EMU international students may lack enough knowledge about usefulness of vocabulary learning strategies. During their language classes, VLS probably have not been introduced for them or if they know anything about them, it is something personal that have been gained by experience or his/her preferred style of learning.

Regarding the second question: what are the most and the least common vocabulary learning strategies applied by international students at Eastern Mediterranean University?, the findings were converging with previous studies (Riankamol, 2008; Amirian \& Heshmatifar, 2013). The most common types of vocabulary learning strategies were metacognitive strategies whereas the least common type of VLSs was social strategies. Amirian and Hashemifar (2013) believe that the best explanation is that vocabulary learning and retention is something more personal and individual than social. They also add that in EFL contexts negotiation of meaning is not necessary; as a result, social strategies are not used widely among EFL learners (as cited in Kafipour, 2006). The other reason could be the educational system in which these students have learned English (Riankamol, 2008). Mostly, there are not any separate sessions for vocabulary 
learning during the courses for language learning. Language learners mostly experience learning vocabulary by themselves either implicitly during the classes that are devoted to learning other skills or in their free time out of the language learning classes. In EFL contexts, teachers mostly focus on the main four skills such as writing, reading, listening, and speaking. They have no time for teaching vocabulary separately. Thus, there is no wonder if language learners tend to learn vocabularies via metacognitive strategies.

Considering the third question: is there any significant difference in vocabulary learning strategy regarding gender, I found that there is a significant difference between male and female international students in their selection of vocabulary learning strategies. The results revealed that males tend to use determination strategies whereas females preferred to use metacognitive strategies. The results of this study confirm the previous researches' findings related to the role of gender in choosing vocabulary learning strategies (Siriwan, 2007; Heidari Soureshjani, 2011). According to Siriwan (2007) females are more strategy user than males when they are trying to learn new vocabulary items. Consequently, they have learned which strategies are more useful for them to learn better due to experience and test of different types of strategy. So, the type of strategy that they use is not only contingent with their style of learning but also differs from males. Moreover, because of the differences exist between males mind and females in their minds, their mental routes for vocabulary learning are completely different. Therefore, what males choose as strategy for learning is more congruent and convergent with the processes in their mind that is completely different from females' (Pourshahian, Rezvani Kalajahi, \& Yousefi Azarfam, 2012). Thus there is significant difference between males and females in their use VLSs.

Finally, the role of level of proficiency in VLS use was the main focus of the forth question of this study. Does English proficiency level affect using vocabulary learning strategies among groups? The analysis of related survey data indicated no significant difference in VLS use among elementary, intermediate, and advanced EMU international students. The finding of this study rejects previous findings regarding proficiency and VLS. Most of the previous findings indicated a significant difference in VLS choice concerning participants' level of proficiency (Barekat \& Karami, 2012; Ajideh \& Jafari, 2013; Lin-Fang, 2013). There might be different reasons why the proficiency level of students has not had any significant effect in VLS use. First, according to Azimi Mohammad Abedi and Baradaran (2013) proficiency level can play an important role in the VLS use if the participants have gained the different levels of autonomy. Holding this idea, it could be assumed that although EMU international students had different levels of proficiency, there was not any significant difference in their VLS use due to their equality in the level of autonomy. Second, the proficiency test might be the reason. The participants were in three groups of proficiency based on the EMU English Proficiency Test. Although the test is assumed as a standard test of English proficiency, it must be reevaluated again to ensure whether it is still reliable; and it has measured the level of proficiency precisely. Any issue with the test might have caused the results of the study to end up with lack of significant difference among groups based on their level of proficiency.

\section{Conclusion}

The results of this study were very amazing. Comparing with findings of the other identical studies in the other EFL contexts, it could be concluded that vocabulary learning strategy use is very context-specific. Different contexts reveal different patterns of VLS use. Moreover, 
personal factors like gender and proficiency are not directly affecting preference for the VLS use among language learners. I found that there is a very complex system with interwoven and interrelated factors that differ from context to context and affects learners VLS use. Factors like previous language learning experiences, autonomy in language learning, self regulation, educational system, the nature of the proficiency test, etc. Thus, if there are courses for vocabulary learning in EFL contexts vocabulary learning strategies must be taught while the mentioned factors are taken into consideration strictly because they can influentially change the outcome of the courses.

Besides, inferring the results of this study, it can also be claimed that: 1 . most of the English teachers may not be aware of the importance of vocabulary learning strategies in Middle East, 2. they are aware but does not consider them as effective factors for learning vocabularies, or 3. they do not teach vocabulary at all. Although proficiency increased, no change in knowledge of VLS revealed. In the other words, even students with high level of proficiency don't know about the importance vocabulary learning strategies. It is the same for both male and female learners. Nation (2001) and Nation and Webb (2010) mention key word method and flash cards as the most influential vocabulary learning strategies that provide permanent effects on the retention of vocabulary learning. Nevertheless, none of the Middle Eastern students was aware of them. Thus, surly we can report that vocabulary learning strategies are ignored in Middle East English classrooms.

Teachers, especially Middle Eastern teachers, must consider vocabulary teaching as one of the major activities in their classrooms. Moreover, they must not only teach vocabulary and vocabulary learning strategies, but also they must help their students to get to the mastery level of them. Because, as mentioned before, strategy learning helps students to be more autonomous. The more autonomous students, the better outcome.

\section{Implications of the Study}

\subsection{Implications for Teachers:}

The findings of this study are very useful for EFL international universities where English preparatory programs and deficiency courses are considered for their international students. The English lecturers could benefit from these results and they can not only involve vocabulary strategy training sessions in their English courses but also be aware of most beneficial type of VLS regarding attributes of each group of learners.

\subsection{Implications for Researchers:}

Researchers can consider the differences that exist between the findings of this study and other identical study in other EFL contexts and go deeper into factors that can affect VLS use. They can consider factors like context, autonomy, self-regulation, educational system, background of the language learners, and vocabulary size of the students and study their effects on VLS use. They can also measure their indirect impact on VLS use in terms of language proficiency level.

\section{References}


Adam, L. (2013). The importance of strategies in EFL vocabulary acquisition. Journal of University of Pecs,1, 1-48.

Ajideh, P., \& Jaffari, A. (2012). Exploring vocabulary learning strategy use of Iranian EFL learners across different proficiency levels. Journal of Basic and Applied Scientific Research, 2(11). 11803-11811.

Amirian, S. M. R., \& Heshmatifar, Z. (2013). A survey on vocabulary learning strategies: A case of Iranian EFL university students. Journal of Language Teaching and Research, 4(3), 636-641.

Asgari, A., \& Mustapha, G. B. (2011). The type of vocabulary learning strategies used by ESL students in the University Putra Malaysia. Journal of English Language Teaching, 4(2), 84-90.

Azimi Mohamad Abadi, E., \& Baradaran, A. (2013). The relationship between learner autonomy and vocabulary learning strategies in Iranian EFL learners with different language proficiency level. International Journal of Applied Linguistics \&English Literature, 2(3), 176-185.

Barekat, B., \& Karimi, S. (2012). Vocabulary learning strategies: The effect of level of proficiency on the strategy use. Science Road Publishing Corporation Journal, 6(1), 7987.

Benson, P. (2001). Teaching and researching: Autonomy in language learning. London: Longman.

Crookall, D., \& Oxford, R. (1990). Vocabulary Learning: A critical analysis of techniques. TESL Canada Journal, 7(2), 9-30.

Dornyei, Z. (2007). Research methods in applied linguistics. Oxford: Oxford University Press.

Fan, M. (2003). Frequency of use, perceived usefulness, and actual usefulness of second language vocabulary strategies: A study of Hong Kong learners. The Modern Language Journal, 87(2), 222-241.

Farhady, H. (2008). Research methods in applied linguistics. Tehran: Payame Noor University Press.

Graves, M. F. (1987). The roles of instruction in fostering vocabulary development. In M. G. McKeown \& M. E. Curtis (Eds.), The nature of vocabulary acquisition (pp. 165-184). Hillsdale, NJ: Erlbaum.

Griffiths, C. (2007). Language learning strategies: Students' and teachers' perceptions. ELT Journal, 61(2). 91-99.

Gu, P.Y. (1994). Vocabulary learning strategies of good and poor chinese EFL learners. The Twenty-Eighth Annual Convention and Exposition (p. 27). Baltimore. 
Hassanzadeh, M., \& Khatib, M. (2011). Vocabulary learning strategies of Iranian upperintermediate EFL learners. Journal of International Education Studies, 4(2), 144-152.

He, Y. (2010). A study of L2 vocabulary learning strategies (Unpublished master dissertation). Kristiansatd University, Sweeden.

Heidari Soureshjani, K. (2011). Gender-oriented use of vocabulary strategies: A comparative study. Journal of Theory and Practice in Language Studies, 1(7), 898-902.

Hogben, D., \& Lawson, M. J. (1996). The vocabulary learning strategies of foreign language students, Language Learning Journal, 46(1), 101-135.

Khezerlou, S., \& Sadeghi, K. (2012). Self-regulated vocabulary strategy use: Implication for CALL and individual variables. MEXTESOL Journal, 36(1), 1-17.

Lachini, K. (2008). Vocabulary learning strategies and L2 proficiency. In K. Bradford Watts, T. Muller, \& M. Swanson (Eds.), JALT 2007 Conference Proceedings. Tokyo: JALT.

Lin-Fang, W. (2013). A study of factors affecting college students' use of ESL vocabulary learning strategies. International Journal of Humanities and Social Sciences, 3(19), 202208.

Nation, I. S. (2001). Learning vocabulary in another language. Cambridge: Cambridge University Press.

Nation, I. S. P. (1990). Teaching and learning vocabulary. Boston, Mass.: Heinle\&Heinle.

Nation, I. S. P., \& Webb, S. (2010). Researching and analyzing vocabulary. Heinle: Boston.

Oxford, R. (1990). Language learning strategies: What every teacher should know. Boston: Newbury House.

Pourshahian, B., Rezvani Kalajahi, S. A., \& Yousefi Azarfam, A. (2012). Does applying vocabulary learning strategies vary based on gender? The case of Turkish EFL learners. Journal of Research on Humanities and Social Sciences, 2(4), 1-10.

Riankamol, N. (2008). A survey study of vocabulary strategies of gifted English students at Triam Udomsuksa school in the first semester of academic year 2008 (Unpublished master dissertation). Thamasat University, Bangkok.

Schmitt N., \& Schmitt, D. (1995). Vocabulary notebooks: theoretical underpinnings and practical suggestions. ELT Journal, 49, 133-243.

Schmitt, N. (1997). Vocabulary learning strategies. In N. Schmitt \& M. McCarthy (Eds.), Vocabulary: description, acquisition and pedagogy (pp.199-228). Cambridge: Cambridge University Press.

Siriwan, M. (2007). English vocabulary learning strategies employed by Rajabhat University students (Unpoblished doctoral dissertation). Suranaree University of Technology, Thailand. 
Willerman, B., \& Melvin, B. (1979). Reservations about the keyword mnemonic. Canadian Modern Language Review, 35,443-453.

\section{Author's Biography:}

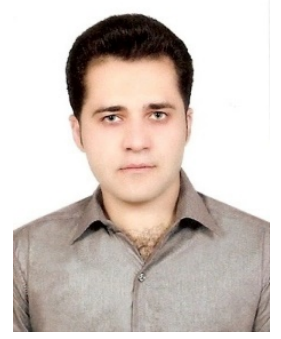

Amin Rasti Behbahani is an Iranian lives in Finland, Jyväskylä. He received his both B.A and M.A in TEFL from Islamic Azad University, Iran. Currently, $\mathrm{He}$ is a PhD researcher in applied linguistics, at the department of languages, university of Jyvaskyla.

He used to work as a lecturer in Islamic Azad University, Behbahan for 4 years. He published a series of book for teaching general and basic academic English for Islamic Azad University, which is titled as: Basic Academic English (Payame Emruz, Tehran, 2013). His main area of interest is vocabulary learning, and video game based learning. Of his papers regarding video games and learning, the effect of video games on EFL learners' vocabulary learning (2013, Reading Matrix) is very important and crucial. 